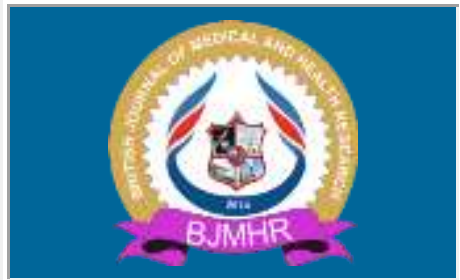

\title{
BJMHR
}

British Journal of Medical and Health Research Journal home page: www.bjmhr.com

\section{Evaluation of Hemodynamic Changes In Retro-Orbital Vessels by Color Doppler In Glaucoma Patients}

\author{
Vemireddy Pradeep Kumar Reddy ${ }^{1^{*}}$, P M Venkata Sai ${ }^{1}$, Ritu Gour ${ }^{1}$ \\ 1.Department of radiology, Sri Ramachandra medical college.
}

\begin{abstract}
In glaucoma, only one-third to half have elevated IOP at initial stages. Hemodynamic parameters measured using Colour Doppler Imaging (CDI) parameters can differentiate eyes suffering from Glaucoma compared to normal eyes early. To evaluate the role of CDI in glaucoma patients and to compare hemodynamic changes and resistive index in Ophthalmic artery (OA), Central retinal artery (CRA), Short posterior ciliary arteries (SPCA) in glaucoma patients and controls. A case control study was conducted on 30 cases of Glaucoma and 30 controls. IOP measurement, fundus examination and CDI was done. The Peak Systolic Velocity (PSV), End Diastolic Velocity (EDV) values, Systolic/ diastolic (S/D) ratio were obtained for the OA, CRA and SPCA. Resistive Index (RI) was calculated as (PSV EDV)/PSV. IBM SPSS version 22 was used for statistical analysis. P value $<0.05$ was considered statistically significant. Chi square test/Fisher's exact test was used for qualitative variables while independent sample t-test was used for quantitative variables. The difference between the two groups was statistically significant with respect to PSV OA and EDV SPCA. The mean difference of RI OA, RI CRA, RI SPCA in the glaucoma group was statistically not significant. ROC curve analysis revealed a good predictive value $(\mathrm{AUC}=0.647)$ for the PSV $\mathrm{OA}$ in predicting Glaucoma. Hemodynamic parameters measured using CDI can differentiate glaucomatous eyes from normal eyes.
\end{abstract}

Keywords: Glaucoma, Retrobulbar blood flow, Colour Doppler Imaging, Primary Open Angle Glaucoma, Normal Tension Glaucoma, Resistive Index. 


\section{INTRODUCTION}

Glaucoma is one of the leading causes of irreversible blindness worldwide. ${ }^{1}$ By 2020, around 80 million people would be suffering from Glaucoma. ${ }^{2}$ Only one-third to half have elevated IOP at initial stages. ${ }^{3}$ Consequently, non-IOP-dependent mechanisms have been proposed. ${ }^{4}$ With recent advances, the focus has shifted to retrobulbar blood flow parameters. ${ }^{5,6}$ Colour Doppler Imaging (CDI) is one of the most commonly used imaging modality for investigating ocular blood flow parameters. ${ }^{7}$ There are huge variations in the strength of association of different retrobulbar blood flow parameters with type, severity of glaucoma ${ }^{5-10}$, with only limited number available in Indian population. ${ }^{11,12}$

\section{MATERIALS AND METHOD}

A case control study was conducted in Sri Ramachandra medical college, Chennai on 30 cases of Glaucoma being referred from M N Eye hospital to Department of Radiology for evaluation of retrobulbar hemodynamic and 30 controls. People screened negative for glaucoma in the glaucoma screening clinic of the same institution were considered as controls. The sample size was calculated assuming a power of $80 \%, 5 \%$ two sided alpha error with a mean Peak Systolic Velocity (PSV) for OA of $31.35+/-6.95 \mathrm{~cm} / \mathrm{s}$ in POAG group and $37.61+/-7.25 \mathrm{~cm} / \mathrm{s}$ in the control group, as per study by Adeyinka $\mathrm{O}$ et al. ${ }^{13} 10 \%$ non-participation rate was also accounted for in both the groups. The data collection was done between September 2016 to March 2018 after getting ethical clearance. Consented participants were recruited sequentially until the required sample size is reached. An informed consent, oral and written was obtained from every patient. The patient attendee was also explained about this study and assured that it was a harmless non-invasive procedure. GE Voluson E8 Ultrasound machine linear probe of frequency 8-10 MHz was used throughout the study. IOP was measured at the eye hospital using gold standard Goldmann applanation tonometer. After careful fundus examination and visual field examination the patients were grouped into Primary open angle glaucoma (POAG), Normal tension glaucoma (NTG) and ocular hypertension (OHT) groups. Any patient with primary angle closure glaucoma and secondary glaucoma were excluded from the study. The radiologist performing the colour Doppler imaging was blinded regarding the diagnosis of the patient to avoid any bias. Ocular Doppler Color Imaging was conducted on subjects in the supine position. With eyes closed and gaze directed at the ceiling, a thick layer of acoustic gel was applied to the closed upper eyelid, and a 9-MHz linear array transducer was placed on the temporal part of the closed upper eyelid with the examiner's hand resting on the orbital margin to minimize pressure on the globe. Pulsed Doppler sonography is performed with the gain optimized such that colour was seen within the vessels and there were no color artefacts allowing the detection of low velocities. Although the CDI device is equipped for measurement 
of blood vessel diameter, the dimension of the retrobulbar blood vessels is too small to obtain a reliable estimation of their diameter. To examine the OA, the sample volume is oriented nasally and superior to the optic nerve. The recording of the blood flow parameters of the central retinal artery and vein is obtained inside the optic nerve, a few millimetres away from the lamina cribrosa. A specific finding of the blood flow in the central retinal vein is its pulsatile character. Short posterior ciliary arteries are visualized in the postero-lateral region of the papilla, on both sides, temporal and nasal, respectively. The Peak Systolic Velocity (PSV) and End Diastolic Velocity (EDV) values are obtained by taking the velocity reading at the peak of the spectral wave pattern and that at the wave trough, respectively. Resistive index (RI) is calculated for OA, CRA and short posterior ciliary arteries as (PSV - EDV)/PSV. The indices of measurement were Resistive index (RI), Systolic/ diastolic (S/D) ratio, Peak systolic velocity, End diastolic velocity and the biphasic flow of ophthalmic artery. Presence and type of glaucoma were considered as the primary explanatory variable. The hemodynamic parameters in different retro-orbital vessels were considered as primary outcome variables of interest. Age, gender was considered as potential confounders. The categorical variables were compared between Glaucoma and Non-glaucoma subjects using cross tabulation and comparison of proportions. Chi square test/Fisher's exact test was used to test the statistical significance of the association. The mean values of the normally distributed quantitative variables were compared between glaucoma and normal subjects, using independent sample ttest. The data was also represented graphically using a comparative error bar. $\mathrm{P}$ value $<0.05$ was considered statistically significant. IBM SPSS version 22 was used for statistical analysis.

\section{RESULTS AND DISCUSSION}

In this study, out of total 60 subjects, 24 were males and 36 were females. A total of 120 eyes were evaluated till sample size was reached 60 eyes constituted the Glaucoma group while 60 eyes constituted the Control group. The number of eyes affected by normal tension glaucoma were $30(25.0 \%)$. 26(21.70\%) had primary open angle glaucoma and remaining 4(3.30\%) had ocular hypertension. There was no difference between the study groups with respect to gender ( $\mathrm{P}$ value 0.136 ) as shown in Table 1.

Table 1: Comparison of gender and hemodynamic parameters between the groups

\begin{tabular}{|c|c|c|c|}
\hline \multirow[t]{2}{*}{ Variables } & \multicolumn{2}{|l|}{ Study group } & \multirow[t]{2}{*}{ P-value } \\
\hline & $\begin{array}{c}\text { Glaucoma(cases) } \\
\mathbf{n}=30 \text { (subjects) } \\
\mathbf{N}=60 \text { (eyes) }\end{array}$ & $\begin{array}{c}\text { Normal (Controls) } \\
\mathbf{n}=30 \text { (subjects) } \\
\mathbf{N}=60 \text { (eyes) }\end{array}$ & \\
\hline \multicolumn{4}{|l|}{ Gender N (\%) } \\
\hline Male & $10(33.3 \%)$ & $14(46.7 \%)$ & 0.136 \\
\hline Female & $20(66.7 \%)$ & $16(53.3 \%)$ & \\
\hline \multicolumn{4}{|c|}{ Ophthalmic Artery (OA) $($ Mean \pm S.D) } \\
\hline PSV OA $(\mathrm{cm} / \mathrm{s})$ & $25.3 \pm 7.98$ & $29.84 \pm 9.28$ & 0.005 \\
\hline
\end{tabular}




\begin{tabular}{llll}
\hline EDV OA $(\mathrm{cm} / \mathrm{s})$ & $5.21 \pm 2.25$ & $6.13 \pm 3$ & 0.059 \\
RI OA & $0.79 \pm 0.06$ & $0.79 \pm 0.08$ & 0.775 \\
S/D OA & $5.28 \pm 1.7$ & $5.66 \pm 2.52$ & 0.342
\end{tabular}

Central Retinal Artery (CRA) (Mean \pm S.D)

$\begin{array}{llll}\text { PSV CRA }(\mathrm{cm} / \mathrm{s}) & 10.72 \pm 4.27 & 10.96 \pm 3.56 & 0.742 \\ \text { EDV CRA }(\mathrm{cm} / \mathrm{s}) & 2.65 \pm 1.1 & 2.89 \pm 1.41 & 0.321 \\ \text { RI CRA } & 0.75 \pm 0.08 & 0.74 \pm 0.08 & 0.589 \\ \text { S/D CRA } & 4.46 \pm 1.75 & 4.37 \pm 1.69 & 0.781\end{array}$

Short Posterior Ciliary Arteries (SPCA) (Mean \pm S.D)

\begin{tabular}{llll} 
PSV SPCA $(\mathrm{cm} / \mathrm{s})$ & $11.12 \pm 3.63$ & $11.8 \pm 3.94$ & 0.324 \\
EDV SPCA $(\mathrm{cm} / \mathrm{s})$ & $2.72 \pm 1.15$ & $3.31 \pm 1.93$ & 0.047 \\
RI SPCA & $0.75 \pm 0.11$ & $0.73 \pm 0.09$ & 0.181 \\
S/D SPCA & $4.57 \pm 2.5$ & $4.25 \pm 2.28$ & 0.457 \\
\hline
\end{tabular}

Among the hemodynamic parameters, the difference between the two groups was statistically significant with respect to PSV OA and EDV SPCA as shown in Figure 1.

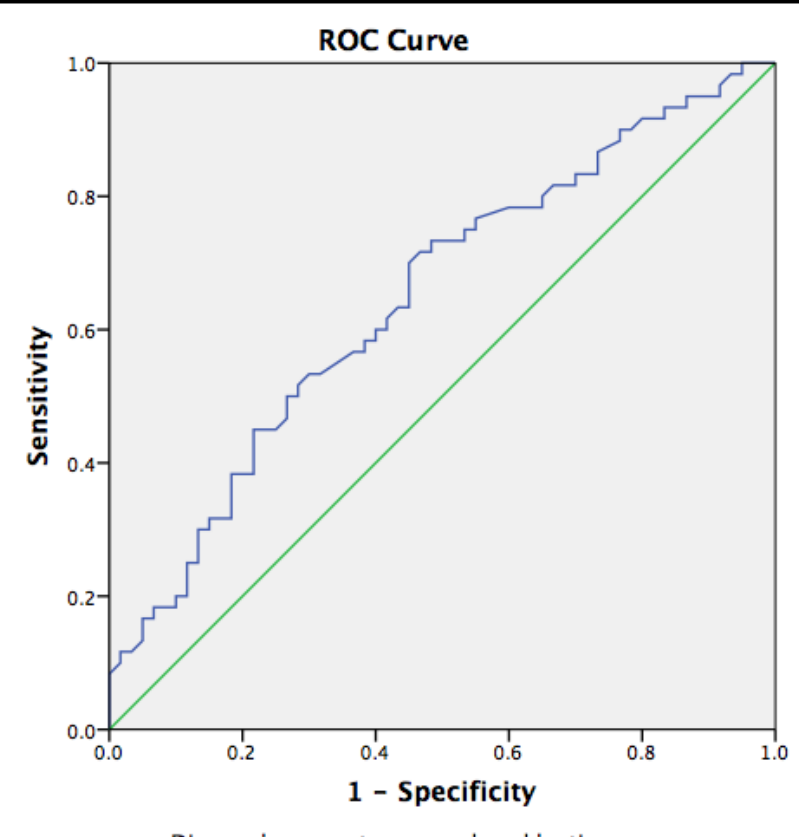

Diagonal segments are produced by ties.

Figure 1: Receiver operating curve analysis to assess the predictive validity of PSV ophthalmic artery in identifying eyes with glucoma

\begin{tabular}{lllll}
\hline \multicolumn{5}{c}{ Test Result Variable(s): PSV OA } \\
\hline Area & Std. Error $^{\mathbf{a}}$ & $\begin{array}{l}\text { Asymptotic } \\
\text { Sig. }\end{array}$ & $\begin{array}{l}\text { Asymptotic 95\% } \\
\text { Lower Bound }\end{array}$ & $\begin{array}{l}\text { Confidence Interval } \\
\text { Upper Bound }\end{array}$ \\
\hline 0.647 & 0.050 & 0.005 & 0.549 & 0.745 \\
\hline
\end{tabular}

b. Null hypothesis: true area $=0.5$

The mean difference of RI OA, RI CRA, RI SPCA in the glaucoma group was statistically not significant $(\mathrm{P}$ value $>0.05)$ as shown in Table 2,3,4.

The area under the ROC curve was 0.647 , indicating a good predictive value of PSV OA in identifying subjects with normal and glaucoma. 
Table 2: Comparison of mean RI OA across the study groups in the study population ( $\mathrm{N}=120$ (eyes))

\begin{tabular}{llllll}
\hline Glaucoma & $\begin{array}{l}\text { RI OA } \\
\text { (Mean } \pm \text { SD) }\end{array}$ & $\begin{array}{l}\text { Mean } \\
\text { difference }\end{array}$ & $\begin{array}{l}\text { 95\% Confidence } \\
\text { Interval for Mean }\end{array}$ & P value \\
\cline { 5 - 6 } & & & $\begin{array}{l}\text { Lower } \\
\text { Bound }\end{array}$ & $\begin{array}{l}\text { Upper } \\
\text { Bound }\end{array}$ & \\
\hline Controls (Normal) & $0.79 \pm 0.08$ & & & & \\
Normal tension glaucoma & $0.8 \pm 0.05$ & -0.01 & -0.04 & 0.02 & 0.698 \\
Primary open angle glaucoma & $0.78 \pm 0.06$ & 0.01 & -0.02 & 0.04 & 0.466 \\
Ocular hypertension & $0.77 \pm 0.05$ & 0.02 & -0.05 & 0.09 & 0.539 \\
\hline
\end{tabular}

Table 3: Comparison of mean RI CRA across the study groups in the study population $(\mathrm{N}=120)$

\begin{tabular}{llllll}
\hline Glaucoma & $\begin{array}{l}\text { RI CRA } \\
\text { Mean } \pm \text { SD }\end{array}$ & $\begin{array}{l}\text { Mean } \\
\text { difference }\end{array}$ & $\begin{array}{l}\text { 95\% Confidence } \\
\text { Interval for Mean }\end{array}$ & \multirow{2}{*}{ P value } \\
\cline { 4 - 5 } & & & $\begin{array}{l}\text { Lower } \\
\text { Bound }\end{array}$ & $\begin{array}{c}\text { Upper } \\
\text { Bound }\end{array}$ & \\
\hline Controls (Normal) & $0.74 \pm 0.08$ & & & & \\
Normal tension glaucoma & $0.74 \pm 0.1$ & 0.00 & -0.04 & 0.04 & 0.877 \\
Primary open angle glaucoma & $0.76 \pm 0.07$ & -0.01 & -0.06 & 0.03 & 0.493 \\
Ocular hypertension & $0.8 \pm 0.08$ & -0.06 & -0.14 & 0.03 & 0.202 \\
\hline
\end{tabular}

Table 4: Comparison of mean RI SPCA across the study groups in the study population $(\mathrm{N}=117)$

\begin{tabular}{llllll}
\hline Glaucoma & $\begin{array}{l}\text { RI SPCA } \\
\text { Mean } \pm \text { SD }\end{array}$ & $\begin{array}{l}\text { Mean } \\
\text { difference }\end{array}$ & $\begin{array}{l}\text { 95\% Confidence } \\
\text { Interval for Mean }\end{array}$ & \multirow{2}{*}{ P value } \\
& & & $\begin{array}{l}\text { Lower } \\
\text { Bound }\end{array}$ & $\begin{array}{l}\text { Upper } \\
\text { Bound }\end{array}$ & \\
\hline Controls (Normal) & $0.73 \pm 0.09$ & & & & \\
Normal tension glaucoma & $0.76 \pm 0.13$ & -0.03 & -0.07 & 0.02 & 0.206 \\
Primary open angle glaucoma & $0.74 \pm 0.08$ & -0.02 & -0.06 & 0.03 & 0.482 \\
Ocular hypertension & $0.77 \pm 0.05$ & -0.04 & -0.14 & 0.06 & 0.404 \\
\hline
\end{tabular}

\section{DISCUSSION:}

Glaucoma is a silent killer of the eye. Blindness from glaucoma is irreversible. By 2020, around 80 million people would be suffering from Glaucoma worldwide. ${ }^{2}$ According to a systematic review estimate, in population aged between forty to eighty years, the worldwide prevalence of glaucoma was $3.54 \% .^{2}$ Globally, glaucoma is the second leading cause of blindness amounting to $8 \%$ in total population with blindness. ${ }^{14}$ According to the national health portal of government of India , nearly 12 million people have been affected with glaucoma and around an estimated 1.2 million people were blind from glaucoma. ${ }^{15}$ Majority (90\%) remain undiagnosed. ${ }^{15}$ Early detection is the key to preserving the quality of life in patients with glaucoma. In considering the huge burden of undiagnosed glaucoma in the country, availability of a reliable evaluation method, to diagnose glaucoma early can have a huge positive impact on the timing of the diagnosis of illness, and its final outcome. Ocular hemodynamic parameters have been proposed to be highly useful in this regard. Hence this case control study 
was done for evaluating the role of Color Doppler in glaucoma. This study findings reveal that ocular hemodynamic parameters have huge potential as a diagnostic tool for glaucoma. PSV Ophthalmic Artery (OA) was the only OA parameter, which has shown a statistically significant difference between subjects with glaucoma and subjects with normal eye. ROC curve analysis revealed a good predictive value $(\mathrm{AUC}=0.647)$ for the PSV OA in predicting Glaucoma. Kurysheva NI et al ${ }^{16}$ observed that in detection of glaucoma early, parameters of ocular hemodynamic status accomplished better than structural parameters.

In our study, both the groups were comparable with respect to gender distribution. Among the hemodynamic parameters, PSV OA and EDV SPCA had a statistically significant difference between the two groups. In the current study, the mean PSV, OA among glaucoma eyes was $25.3 \pm 7.98$ and the normal (control) was $29.84 \pm 9.28$, the comparison between two groups was statistically significant (P value 0.005). In the current study, the mean PSV, EDV and SD of Ophthalmic artery were slightly higher among glaucomatous eyes, in comparison with normal eyes, but without statistical significance. The mean resistive index was similar in both glaucoma and normal eyes. In this study, none of the Central Retinal artery flow parameters or RI had shown any statistically significant difference between the two groups. In the current study, the only SPCA parameter, which has shown the statistically significant difference across the groups was mean EDV. In glaucoma (cases) eyes, it was $2.72 \pm 1.15$, and in the normal (control) eyes, it was $3.31 \pm 1.93$ (P value 0.047 ). Moore NA et al ${ }^{17}$, in their study observed that subjects who progressed structurally had lower baseline mean ophthalmic artery PSV $(\mathrm{p}=0.024)$ and ophthalmic artery EDV $(\mathrm{p}=0.012)$ in comparison to those who did not progress. Stalmans $\mathrm{I}$ et $\mathrm{al}^{18}$, in their study observed findings contrast to the current study findings. They observed in comparison to normal subjects, systolic and diastolic blood flow velocities decreased in the retrobulbar vessels of NTG $(\mathrm{P}=0.0004)$ and primary OAG $(\mathrm{P}=0.003)$. Samsudin A et $\mathrm{al}^{19}$, reported that there were no significant differences in ocular perfusion pressure, EDV,PSV, RI between the NTG and control groups ( $p>0.05)$. These study findings were similar to the findings of our current study. Yamazaki $\mathrm{Y}$ et $\mathrm{al}^{20}$, reported that there were no significant differences in ophthalmic arterial flow parameters between subjects with POAG and NTG. But they observed a correlation between RI and MD in NTG subjects which was significant statistically. Their results suggested that in NTG, development of visual field defects may be related with vascular resistance of the ophthalmic artery. As per Marjanovic, I et $\mathrm{al}^{5}$, in open-angle glaucoma (OAG) patients, there was no difference with gender in various ocular blood flow parameters. As per a study by Adeyinka OO et $\mathrm{al}^{21}$, mean PSV for OA was $31.35 \mathrm{~cm} / \mathrm{s}$ in POAG group while it was $37.61 \mathrm{~cm} / \mathrm{s}$ in normal subjects $(\mathrm{P}<0.001)$. In comparison with normal subjects, the EDV for OA and CRA was lesser in glaucoma patients $(\mathrm{P}<0.001)$. Marjanovic I et $\mathrm{al}^{22}$, in their study observed that RI values were significantly 
increased in both the ophthalmic $(\mathrm{P}=0.003)$ and short PCA $(\mathrm{P}=0.048)$ in the OAG patients on comparing it with subjects with ACG. Marjanovic, I., et $\mathrm{al}^{23}$, also observed that after decreasing the elevated IOP, on comparing baseline parameters in subjects with OAG, the retrobulbar parameters did not show any difference. In contrast to current study findings, Januleviciene, I et $\mathrm{al}^{24}$, observed that there was decreased blood flow in retro bulbar vessels in subjects with OAG related with thinning of the RNFL. Among glaucoma patients, only one-third to half have elevated IOP at the initial stages. It can be concluded from the results of our study that hemodynamic parameters measured using colour Doppler imaging parameters can differentiate eyes suffering from Glaucoma compared to normal eyes early. None of the CRA parameters had shown the statistically significant difference between the normal and diseased eyes. Among the ophthalmic artery parameters, only the PSV values were significantly decreased in glaucoma eyes as compared to controls with a good predictive value (AUC $=0.647$ ) while the mean EDV was reduced significantly in diseased eyes as compared to controls among SPCA parameters. The values of Retro bulbar vessels RI did not show any statistically significant differences between normal eyes and glaucoma types.

\section{CONCLUSION:}

The generalizability of the study findings is limited, as the study has been conducted in a single centre and the retrobulbar parameters have shown wide variation across the studies depending on the composition of the study population. The lack of statistical significance of many of the differences between the study groups may be attributed to smaller sample size. The role of potential confounding by key variables like gender, the presence of comorbidities etc. also, could not be assessed due to a smaller sample size of the study. There is a need for large-scale multicentric studies on the subject, to enhance the quality of available evidence on the Indian population. Till such quality evidence is awaited, it is difficult to make any strong clinical practice recommendations.

\section{ACKNOWLEDGEMENT:}

We acknowledge the technical support in data entry, analysis and manuscript editing by "Evidencian Research Associates"

\section{REFERENCES:}

1. Ben Salem C, Fathallah N, Zayani H. Glaucoma. Lancet. 2018;391(10122):739-40.

2. Tham YC, Li X, Wong TY, Quigley HA, Aung T, Cheng CY. Global prevalence of glaucoma and projections of glaucoma burden through 2040: a systematic review and meta-analysis. Ophthalmology. 2014;121(11):2081-90.

3. Susanna R, Jr., De Moraes CG, Cioffi GA, Ritch R. Why Do People (Still) Go Blind from Glaucoma? Transl Vis Sci Technol. 2015;4(2):1. 
4. Abegao Pinto L, Willekens K, Van Keer K, Shibesh A, Molenberghs G, Vandewalle E, et al. Ocular blood flow in glaucoma - the Leuven Eye Study. Acta Ophthalmol. 2016;94(6):592-8.

5. Marjanovic I, Marjanovic M, Gvozdenovic R, Risovic D. Retrobulbar hemodynamic parameters in men and women with open angle glaucoma. Vojnosanit Pregl. 2014;71(12):1128-31.

6. Kuerten D, Fuest M, Koch EC, Koutsonas A, Plange N. Retrobulbar Hemodynamics and Visual Field Progression in Normal Tension Glaucoma: A Long-Term Follow-Up Study. Biomed Res Int. 2015; 2015:158097.

7. Xu S, Huang S, Lin Z, Liu W, Zhong Y. Color Doppler Imaging Analysis of Ocular Blood Flow Velocities in Normal Tension Glaucoma Patients: A Meta-Analysis. J Ophthalmol. 2015; 2015:919610.

8. Magureanu M, Stanila A, Bunescu LV, Armeanu C. Color Doppler imaging of the retrobulbar circulation in progressive glaucoma optic neuropathy. Rom J Ophthalmol. 2016;60(4):237-48.

9. Costa VP, Harris A, Anderson D, Stodtmeister R, Cremasco F, Kergoat H, et al. Ocular perfusion pressure in glaucoma. Acta Ophthalmol. 2014;92(4):e252-66.

10. Marjanovic I, Milic N, Martinez A, Benitez-del-Castillo J. Retrobulbar hemodynamic parameters in open-angle and angle-closure glaucoma patients. Eye (Lond). 2012;26(4):523-8.

11. Paul C, Sengupta S, Banerjee S, Choudhury S. Angle closure glaucoma in rural and urban populations in eastern India-The Hooghly River Glaucoma Study. Indian J Ophthalmol. 2018;66(9):1285-90.

12. Vijaya L, Rashima A, Panday M, Choudhari NS, Ramesh SV, Lokapavani V, et al. Predictors for incidence of primary open-angle glaucoma in a South Indian population: the Chennai eye disease incidence study. Ophthalmology. 2014;121(7):1370-6.

13. Adeyinka OO, Olugbenga A, Helen OO, Adebayo AV, Rasheed A. Ocular blood flow velocity in primary open angle glaucoma--a tropical African population study. Middle East Afr J Ophthalmol. 2013;20(2):174-8.

14. Pascolini D, Mariotti SP. Global estimates of visual impairment: 2010. Br J Ophthalmol. 2012;96(5):614-8.

15. National Health Portal. World Glaucoma Week [Internet]. CHI, NIHFW, MoHFW; 2019 [cited 2020 Feb 10]. Available from: https://www.nhp.gov.in/worldglaucoma-week_pg. 
16. Kurysheva NI, Parshunina OA, Shatalova EO, Kiseleva TN, Lagutin MB, Fomin AV. Value of Structural and Hemodynamic Parameters for the Early Detection of Primary Open-Angle Glaucoma. Curr Eye Res. 2017;42(3):411-7.

17. Moore NA, Harris A, Wentz S, Verticchio Vercellin AC, Parekh P, Gross J, et al. Baseline retrobulbar blood flow is associated with both functional and structural glaucomatous progression after 4 years. Br J Ophthalmol. 2017;101(3):305-8.

18. Stalmans I, Harris A, Fieuws S, Zeyen T, Vanbellinghen V, McCranor L, et al. Color Doppler imaging and ocular pulse amplitude in glaucomatous and healthy eyes. Eur J Ophthalmol. 2009;19(4):580-7.

19. Samsudin A, Isaacs N, Tai ML, Ramli N, Mimiwati Z, Choo MM. Ocular perfusion pressure and ophthalmic artery flow in patients with normal tension glaucoma. BMC Ophthalmol. 2016;16:39.

20. Yamazaki Y, Hayamizu F. Comparison of flow velocity of ophthalmic artery between primary open angle glaucoma and normal tension glaucoma. $\mathrm{Br} \mathrm{J}$ Ophthalmol. 1995;79(8):732-4.

21. Wong SS, Oshansky CM, Guo XJ, Ralston J, Wood T, Seeds R, et al. Severe Influenza Is Characterized by Prolonged Immune Activation: Results From the SHIVERS Cohort Study. J Infect Dis. 2018;217(2):245-56.

22. Marjanovic I, Martinez A, Marjanovic M, Milic N, Kontic D, Hentova-Sencanic P, et al. Changes in the retrobulbar hemodynamic parameters after decreasing the elevated intraocular pressure in primary open-angle glaucoma patients. Srp Arh Celok Lek. 2014;142(5-6):286-90.

23. Marjanovic I, Milic N, Martinez A. The impact of intraocular pressure reduction on retrobulbar hemodynamic parameters in patients with open-angle glaucoma. Eur J Ophthalmol. 2012;22(1):77-82.

24. Januleviciene I, Sliesoraityte I, Siesky B, Harris A. Diagnostic compatibility of structural and haemodynamic parameters in open-angle glaucoma patients. Acta Ophthalmol. 2008;86(5):552-7.

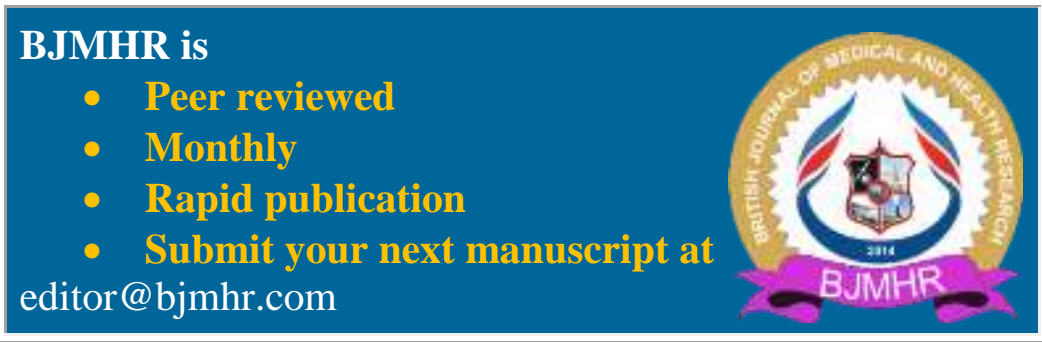

